\title{
BRAF NM_004333.4:C.1790T>A
}

National Cancer Institute

\section{Source}

National Cancer Institute. BRAFNM 004333.4:C.1790T>A. NCI Thesaurus. Code C98331.

A nucleotide substitution at position 1790 of the coding sequence of the BRAF gene where thymine has been mutated to adenine. 